INTERNATIONAL DESIGN CONFERENCE - DESIGN 2018

https://doi.org/10.21278/idc.2018.0164

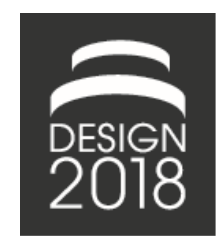

\title{
POSITION PAPER: ON DESIGN RESEARCH ENGAGING WITH HEALTHCARE SYSTEMS
}

\author{
G. Lamé
}

\begin{abstract}
This position paper intends to trigger a debate on the engagement of the design research community with healthcare systems. We analyse the specificities of healthcare systems design and of healthcare organisations. We discuss the focus on evaluation and the evidence-based paradigm in healthcare, and argue that design research currently is ill-prepared to meet such expectations. Dedicated research attention in healthcare seems necessary to bridge this gap. It could enrich design research through multidisciplinary collaborations, and enable design to make a precious contribution to healthcare.
\end{abstract}

Keywords: healthcare design, design research, multi-/cross-/trans-disciplinary approaches

\section{Introduction}

In this position paper, our aim is to trigger a debate on the current engagement of the design research community with healthcare systems. We propose that the specificities of the healthcare sector justifies dedicated attention. We suggest that the engagement of the design research community in healthcare could be improved, notably through interdisciplinary collaborations. We argue that design has much to bring to, and much to learn from, healthcare systems and the other academic disciplines already more active in this sector. Our analysis relies on a selective review of a multidisciplinary literature, from design research, health services research, clinical research, management research and operational research. We end on a promising note, highlighting recent efforts from design researchers to engage with the healthcare sector.

The challenges facing modern healthcare delivery systems are huge - An ageing population, lifestyles that lead to poor health, growing public expectations, rising cost of modern technologically driven interventions and complex clinical conditions that demand effective multi-disciplinary and multiinstitutional working (Clarkson et al., 2017). In addition to these challenges, there is a growing pressure on the healthcare system in the UK to cut cost and achieve better outcomes with less resources (Appleby et al., 2014).

With these challenges, it is not surprising that healthcare is not only turning to other disciplines to help find solutions but other disciplines are developing a growing interest in healthcare.

Different disciplines close to engineering design have seen the development of streams of research and practice dedicated to the healthcare sector. In operational research (OR), INFORMS (Institute for Operations Research and Management Science) has an annual INFORMS Healthcare conference, and the European Working Group on Operational Research Applied to Health Services holds the ORAHS (OR applied to health services) conferences. At least two OR journals are published to support this research stream (Health Care Management Science, Operations Research for Health Care). Management research does the same, with dedicated outlets (e.g. Health Care Management Research), interest groups (e.g. in the Academy of Management, or in the European Health Management 
Association), various conferences and sections in top journals (e.g. in Journal of Operations Management). Biomedical engineering has its own research community, with 77 journals indexed in Clarivate's 2017 Journal Citation Reports. Health policy is in the same situation, and health economics also gathers an important community, with dedicated outlets and conferences.

With this backdrop, it is surprising that the Design Society, the leading scientific society in engineering design, appears to have little interest in healthcare as demonstrated by the relatively limited healthcare content of its two premier conferences, ICED and DESIGN (see Section 5 for examples). Should the Design Society promote a dedicated healthcare stream of research? Are the healthcare challenges out of the domain of engineering design research, are they specific enough to justify dedicated attention, or should the healthcare sector only be regarded as a particular case of applying a more general discipline? Our position is that engineering design can make a significant contribution to addressing the challenges of healthcare delivery systems. However, to do so, design research needs to develop a strong strand of research in healthcare. Some characteristics of the healthcare sector justify this development if we want design research to make more impact on the healthcare sector. We see three main reasons for that, which are developed in Section 2:

- Product design in healthcare exhibits important specificities compared to other industries. Specific design processes and methods are required to meet the regulatory constraints.

- Healthcare organisations differ to a great extent from the industries where design research has traditionally evolved. This makes the transfer of methods developed in other sectors challenging.

- Healthcare is a knowledge-intensive sector, but the research standards are quite different from those of design research. Today, design research is ill-equipped to produce the kind of research products that healthcare professionals are accustomed to.

In this situation, we argue that healthcare design research requires a dedicated approach, with specific research products (e.g. design methods) and specific research competences. We also argue that design research can only make an impact on the healthcare sector if it engages in cross-disciplinary initiatives with other disciplines involved in healthcare research, in order to produce research products that are acceptable in the eyes of those who should use them.

The development of this stream of research practice has already started and it comes with great opportunities for design research to make an impact in healthcare. By collaborating with other disciplines involved in research in the healthcare sector, design could complement the evaluation-driven mode of research. A full continuum could be enacted, from design to evaluation. In return, we believe that design research could learn a lot on how to evaluate its proposals by working with disciplines who have developed appropriate methods to do so.

In the next section, we describe the specificities of healthcare systems design and of healthcare organisations. We then turn to the challenges of design research practice in the healthcare sector. This leads us to identify opportunities to overcome these challenges. The final section synthesises the arguments and discusses the advantages that design research in general could draw from the development of a strong healthcare stream of research practice.

\section{The context: Specificities in the healthcare sector}

\subsection{Healthcare systems design}

Healthcare systems design covers a wide range of systems, from medical devices (Medina et al., 2013b) to complex product-service systems, e.g. telemedicine systems (Duong, 2016). We argue that the process often differs from the ones found in other industries, because of contextual specificities. First, there is a great variety of stakeholders in healthcare design (Yock, 2015). The ultimate beneficiaries are often to be patients, but many other people may be affected: supporting relatives, healthcare professionals, and even society more widely through funding schemes. With this diversity of actors, the repartition of value between stakeholders is a major determinant of the success of failure of an innovation (Langley and Denis, 2011). Although other sectors may involve a wide variety of actors (e.g. the network of suppliers in aircraft production), they are often more homogenous in their industrial culture and in their expectations. 
Second, healthcare is a heavily regulated industry. The validation of medical products is a long process involving various public agencies (Medina et al., 2013a). Dedicated models have been developed to integrate this aspect during the design stages (Medina et al., 2013b). One may argue that the same is true for all high-risk industries, like nuclear or aerospace. What differs here is that in many countries, the validation process includes an evaluation of the benefit of the product, because they will be reimbursed by health insurance. The regulator does not care if a plane is economically viable: the market will decide. The evaluation is here to guarantee that the plane is safe enough with respect to existing standards. In the case of healthcare, the situation is different. The drug needs to be effective, but its benefits also must balance the cost of supporting it through social insurance mechanisms.

Finally, healthcare systems design relies heavily on clinical expertise. However, physicians are trained in a very different cultural system than engineers, which are the prime interlocutors of engineering design researchers in many other sectors. Physicians are experts at diagnosing diseases and prescribing treatments, but often have little knowledge of industrial and business processes (Levy et al., 2015). In the traditional sectors where design research developed and now strives, e.g. automotive, aerospace and defence, design engineering researchers will often discuss with engineering practitioners. This is not the case in healthcare.

\subsection{Healthcare organisations}

\subsubsection{Nature of healthcare organisations}

Healthcare organisations have routinely been described as complex (Georgopoulos and Matejko, 1967; Klein and Young, 2015). Besides the size of health systems and the multiplicity of interacting components that form them, a major element in these descriptions is the large number of stakeholders. One could say that the same is true in regulated sectors, as with transportation networks or energy producers. However, the reality is even more complex in healthcare, because pressures are both external and internal. Healthcare networks exhibit both organizing and strategizing pluralism: pressures from external stakeholders to enact multiple conflicting strategies (research excellence, community care, prevention, complex care, medical education), but there are also pressures from a variety of internal stakeholders to enact different cultures and identities (of healthcare organisations as a clinical centres for cure, as economic actors, as community service providers, as places for care and compassion) (Jarzabkowski and Fenton, 2006). This reflects on the structuring of healthcare organisations, where professional management is balanced by the influence of senior physicians. To succeed, change initiatives require that coalitions be built between the medical and administrative power lines (Denis et al., 2001).

\subsubsection{Transferring industrial approaches to healthcare organisations}

It has often been suggested that healthcare should learn from industrial practice in other sectors. As a result, there have been repeated attempts to transfer methods from industry to healthcare. This is often based on conceptual views of the similarities between these organisations, e.g. views of healthcare systems as service organisations processing flows of patients and operations (Tien and GoldschmidtClermont, 2009; Zhong et al., 2017). However, many attempts to transfer industrial practices to healthcare have been disappointing, due to the aforementioned specificities of healthcare organizations. Some examples in management and operational research have been well documented. For instance, the transfer of discrete-event simulation from industry to healthcare has seen mixed results. More and more papers are published, but implementation levels are very low, suggesting a limited impact on healthcare practice (Brailsford et al., 2009). The situation of healthcare is specific. Jahangirian et al. (2012) found that only $8 \%$ of simulation papers in healthcare involved "a significant level of user/stakeholder engagement in the simulation part", as opposed to "hypothetical Problem-Solving papers" or "methodological papers", whereas "real problem solving papers" accounted for $49 \%$ of the simulation papers in commerce and 39\% in defense. Cultural, practical and political aspects have been identified to explain this situation (Tako and Robinson, 2014; Jahangirian et al., 2015). Overall, modellers agree that "simulation in healthcare is different" (Tako and Robinson, 2014). The same discussions have occurred regarding lean management (Young and McClean, 2008; Radnor et al., 2012). 
In attempts to explain these failures, Lozeau et al. (2002) show how the distance between the assumptions built-in in certain methods (e.g. strong hierarchical structure with central power in the hands of the CEO) may be too far from the reality of healthcare organizations. Similarly, Radnor et al. (2012) identify discrepancies between the fundamental assumptions behind lean management as developed in manufacturing and the way healthcare systems work. As a result, projects based on methods that are too far from the reality of healthcare organisations can become political instruments that each party tries to use to their advantage (Lozeau et al., 2002).

These examples illustrate that the direct transfer of methods from industry to healthcare is often difficult and could even have detrimental side effects. It supports the case for developing dedicated approaches, based on a deeper understanding of healthcare systems. However, researchers who try to do so face challenges in research practice.

\section{Challenges in research practice}

\subsection{Methods and types of findings in medical research: The weight of evaluation}

The healthcare industry is a knowledge-intensive sector. Physicians are expert professionals trained for more than ten years before they can be independent practitioners. The field is also changing fast as medical research keeps offering new therapeutics, new means of diagnosis and new ways to combine medical tools to improve patients' health. Academic hospitals are major centres for clinical research.

In that context, healthcare policy-makers emphasise the need to rely on scientific evidence to guide clinical practice. This came from studies in the years 1960 to 1980, which have evidenced variations in practice between physicians, and of persistence of practices that research had discarded. As a result, inappropriate care was delivered, e.g. (Chassin et al., 1987). At the same time, no robust evidence was available to support some practices. In reaction to this situation, a movement emerged in Canada to use the methods of public health, epidemiology and biostatistics to evaluate clinical practice and decisionmaking. The objective was to inform future medical decisions based on scientific knowledge and to reduce reliance on intuition and un-scientific guidelines. This movement became known as "evidencebased medicine" (Sackett et al., 1996), which promotes the use of state-of-the art scientific knowledge to inform clinical practice. Using the best evidence available is now considered a moral obligation in medical practice (Borry et al., 2006). The movement has spread to other areas, such as healthcare management and policy-making (Walshe and Rundall, 2001) (where the evidence would come from different sources and methods, and be of different nature, than in clinical contexts).

Partly because of this movement, research products are very different in healthcare and in design research. Healthcare research emphasises description, evaluation and explanation. The "golden standard" in clinical research is the Randomised Clinical Trial (RCT), where patients are randomly allotted in two groups, and one group receives a given intervention (e.g. a new treatment) while the other is a control group (e.g. receiving the standard treatment). Statistical analysis is then carried to determine the effect of the intervention on the patients. As results from RCTs accumulate, evidence can be evaluated in systematic reviews, which review and synthesise the results of all trials on a specific intervention. Some of them will go as far as carrying meta-analysis, i.e. quantitative analysis on a sample grouping all patients in the reviewed studies. The objective is to assess whether interventions are clinically effective, i.e. whether they produce the intended effect on patients.

To achieve this level of analysis, methods have to be standardised so that there is confidence that results can be compared. Internal validity is particularly scrutinised (Glasgow et al., 2006), to ensure that the appropriate methods are used to derive results from empirical data. The research community shows a constant effort to standardise trial designs, statistical methods and measurement tools (e.g. biological lab tests, or patient questionnaires) across the discipline.

In parallel to evidence-based medicine and clinical evaluation, economic evaluation has received increasing attention (Gray and Wilkinson, 2016). Because of the social funding of healthcare systems in most countries, authorities have to ensure that this money is well invested before validating the funding of a healthcare intervention. It means assessing whether that the impact of the intervention is worth its cost. Budgets are finite, and choices must be made between different interventions, so the most socially useful ones should be funded in priority. Economic evaluations span from system-level 
initiatives to health-technology assessments. Here again, methods have been progressively standardised (Gray and Wilkinson, 2016).

Qualitative research has also been used for evaluation in the healthcare literature. The principles differ from those used in quantitative research, but a similar effort has been produced to establish quality criteria (Mays and Pope, 2000), rigour and methods have been discussed (Mays and Pope, 1995; Malterud, 2001) and publication guidelines have been issued (Tong et al., 2007) to bring coherence to the field. However, because of the predominant positivist paradigm, qualitative research is still more difficult to publish in the main medical journals (Greenhalgh et al., 2016).

To summarise, healthcare research focuses heavily on evaluation. Products, drugs, technologies, care processes, policies, prevention programmes: most areas of the medical world are subject to evaluation. A range of methods has been developed and refined to evaluate interventions of various kinds. However, the early stages, when interventions are developed, often go largely unreported. Trial and error (albeit evaluated by elaborate methods) is the main approach on some aspects, like health services design. The contemporary design perspective is largely absent in health services management (Clarkson et al., 2004).

\subsection{Contrast with design research}

The landscape in design research is very different. Design research is a relatively new discipline, especially compared to medicine. Design research is still less structured than other more established fields. In 2009, Blessing and Chakrabarti identified three main issues in design research:

- The lack of overview of existing research;

- The lack of use of results in practice;

- The lack of scientific rigour.

These three points can be challenging when discussing with medical researchers. Because research is not as classified as in medicine, the practice of systematic reviews is challenging. The definition of design methods (one of the main products of design research) is itself not clear (Gericke et al., 2017), making comparative studies difficult to carry.

Design research focuses on the production of new objects, be they systems or methods. However, in published design studies, validation is often not even discussed (Barth et al., 2011). The trend seems to be more towards a flourishment of new methods, most of which are not evaluated beyond a few case studies (Blessing and Chakrabarti, 2009). Overall, design research today design seems ill-equipped to debate directly with clinical research on evidence-based grounds, with only scant discussions on validity and evaluation of design methods (Frey and Dym, 2006; Seepersad et al., 2006; Blessing and Chakrabarti, 2009).

Why does this matter? Design research can exist in its own right and live by its own standards, as it has done successfully. Since its inception, design research has positioned itself as different both from natural sciences and humanities (Vermaas, in Papalambros et al., 2015). However, in order to make an impact on healthcare practice, design research will need to produce evidence that can be accepted by those who need to apply it. In the words of others, "The persuasiveness of a theory is in the "eyes" of the listener (not just the speaker) and requires appreciating the context and assumptions of the audience or listeners." (van de Ven and Johnson, 2006, p. 804) The challenge is to make a step in that direction, without losing design's strengths, originality and essence. We argue that this calls for an interdisciplinary approach in healthcare, where design can make a major contribution.

\section{Opportunities for interdisciplinary design research in healthcare}

\subsection{Rationale for interdisciplinary approaches}

When engineering large-scale complex systems, such as transportation systems, IT infrastructures or satellite constellations, multiple disciplines need to be involved. Design engineers have long worked alongside mechanical engineers, electrical engineers, software engineers, etc. on such issues.

Healthcare presents similar challenges. Integrated economic, organisational, social, clinical and technical challenges have to be overcome. Yet as discussed in Section 2, the players are quite different. Design engineers will deal with clinicians of various specialties, nurses, health economists and social 
scientists, none of which have been trained in a design paradigm. In the design of cyber-physical systems, engineering is the dominant perspective. In healthcare, multiple perspectives co-exist and the design approach is rather new. Therefore, we argue that there is more heterogeneity in the actors, and less awareness of design.

We have proposed in Section 3 that the type of findings needs to be acceptable by the people who will use them. Therefore, taking a multidisciplinary approach is not only needed as applying knowledge from different disciplines on the same phenomenon, in order to design a system that is viable under the various laws of nature and society. The challenge is also to generate knowledge in a format that can be accepted by the standards of the field. Otherwise, design research will remain an isolated island in healthcare research. To overcome this challenge, we argue that design must pair with other more evaluative disciplines, to enact a continuum from design to evaluation.

\subsection{Complementarities: A continuum from design to evaluation}

The idea that design and evaluation are complementary is already discussed in management research. Faced with a situation where management research was mostly explanatory research, voices have risen to promote design research as an alternative and complementary perspective (Holmström et al., 2009; van Aken and Romme, 2009). An insightful contribution from this debate is the proposition of a continuum between design research and explanatory research by Holmström et al. (2009). Their framework is reproduced in Figure 1.

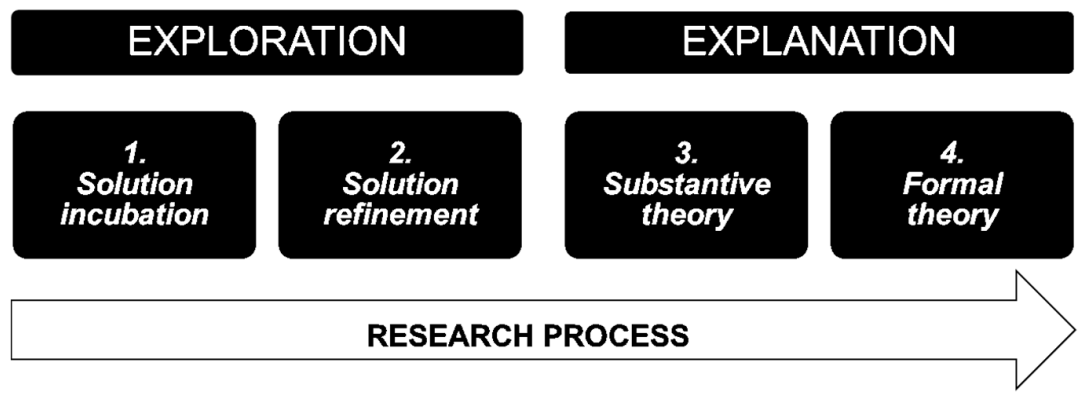

Figure 1. Research process from design to theory, based on Holmström et al. (2009)

In this continuum, research starts with a practical problem to which solutions have to be found. In the exploration phase, solutions are proposed and refined. A first evaluation of their effectiveness is proposed through implementation in a limited number of cases. This is design research as we often know it today, with abductive reasoning, iterative cycles of improving and testing the solution.

Once a good candidate has been identified, it can be evaluated using the methods of explanatory research. The objective is to integrate the solution inside the theoretical corpus and to generate new theoretical propositions based on this solution. This starts with mid-range substantive theory, which is tied to a particular context, and ends with formal theory, which is generic and applies to any context. The hypothetico-deductive mode is used in this phase. A theory is built around the solution to explain how it affects practice. From this theory, hypothesis are derived which can be tested empirically.

We believe that this process can apply to design research in healthcare. It can reconcile the need for creative approaches and structured systems design with the demand for evidence-based practice. Management and medicine are, arguably, design sciences (van Aken and Romme, 2009; Johannesson and Perjons, 2014), although their research product focus more on evaluation than on design. This collaborative research process could re-emphasise the design dimension by promoting more consideration for the generative stages, thus better balancing design and evaluation, exploration and explanation.

\subsubsection{Exploration}

Exploration is where design research can typically make a great impact on healthcare. This phase is where interdisciplinary approaches will be useful to identify solutions to practical problems. Nair et al. (2008) have studied the experience of interdisciplinary research in healthcare. The researchers they 
interviewed participated in interdisciplinary research to answer specific problems, for which a dedicated team was created. The objective was to combine different perspectives to study complex phenomena. This type of approaches yielded richer results than separate disciplinary projects.

The issue-based nature of the collaborations described by Nair et al. (2008) is similar to the Mode 2 of research (Nowotny et al., 2003). Mode 1 is traditional, disciplinary research. In Mode 2, research is oriented towards impact, and knowledge is generated in a given context through transdisciplinary enquiry. As disciplinary boundaries are irrelevant in this research, quality is harder to measure in the terms of each discipline. This type of research requires specific practices and collaborations to be elaborated, such as in van de Ven and Johnson's "engaged scholarship" (van de Ven and Johnson, 2006). Design is well fit for this type of context. In a context of problem-solving research, design sciences like design engineering or operational research can play a mediating role between disciplines (Crowe et al., 2017). However, given the specificities of healthcare organisations, there may also be a need for "interdisciplinary specialists". These are people specialising in a particular interdisciplinary area, as opposed to pluridisciplinary experts trained in two separate disciplinary traditions (Greene et al., 2016). These people could help bridge disciplinary gaps and establish common language.

The modelling and simulation tools used in design can avoid long trial-and-error cycles in the exploratory stage. Thinking in systems, prospectively accounting for risks, considering value repartition, integrating users in design: the whole repertoire of design engineers can be used here. Therefore, design engineers can play a leading role in pluridisciplinary collaborations in the exploratory phase.

\subsubsection{Evaluation}

Evaluation is where design research typically struggles (Blessing and Chakrabarti, 2009; Barth et al., 2011). In these stages, design researchers will probably need support from researchers from disciplines traditionally more oriented towards evaluation. The challenge will be to identify the right approach to evaluate the solution to a problem. Some solutions will fall in traditional categories of economic and clinical evaluation, for instance in Health Technology Assessment (Banta, 2003). For instance, the evaluation of new types of medical devices can be evaluated through randomised clinical trials combined with an economic analysis.

For other interventions, like service design or workplace design, parallels can be drawn with complex healthcare interventions. These interventions involve an array of interrelated factors, it is difficult to identify independent and dependant variables, and context may play a major role in the success of the intervention. Randomised controlled trials can sometimes be used in these cases (Campbell et al., 2007), but a whole range of other methods can help. In particular, methods used in the evaluation of improvement projects in health services could be useful (Portela et al., 2015).

In all cases, although the evidence-based rhetoric has become very pervasive in healthcare, it is important to understand what evidence is needed, and how it can be generated. RCTs are effective to answer some questions, but other methods can be complementary or more suitable to inform other decisions.

\section{Discussion}

\subsection{Importance and role of design in healthcare}

In this paper, we have argued that the specificities of the healthcare sector warrant a dedicated approach to healthcare design. We have shown that healthcare is different from the sectors where engineering design research has traditionally emerged, i.e. manufacturing industry.

Healthcare needs design, as expressed by researchers from a variety of perspectives (Plsek, 1997; Clarkson et al., 2004; Reid et al., 2005; Mathews and Pronovost, 2011; Wears, 2017). However, to succeed and be accepted, design research needs to be acceptable by healthcare standards, which focus much more on evaluation. Today, publications suggest that design research is not ready yet to perform evaluation as expected in healthcare research. Although this may seem discouraging, a way forward is a collaboration between design researchers and researchers from evaluation-oriented disciplines. Figure 2 illustrates (very schematically) the types of interactions that could be expected. It involves an adaptation of design and modelling and simulation (M\&S) methods from design to healthcare, and the 
adaptation of evaluation methods from evaluative disciplines to design. This is not a simple task, and the shortcomings of controlled trials and positivist evaluations for design research have already been discussed (Seepersad et al., 2006). However, when evaluation of design research is not possible using traditional evaluation approaches in healthcare, it is important that we can show it by defining more precisely validity criteria for our research products and appropriate evaluation methods. To do this, we must understand the prevalent codes and practices and propose sensible alternatives. Only then can we propose evaluation methods that apply to our research (and that could then also be used for other healthcare research).

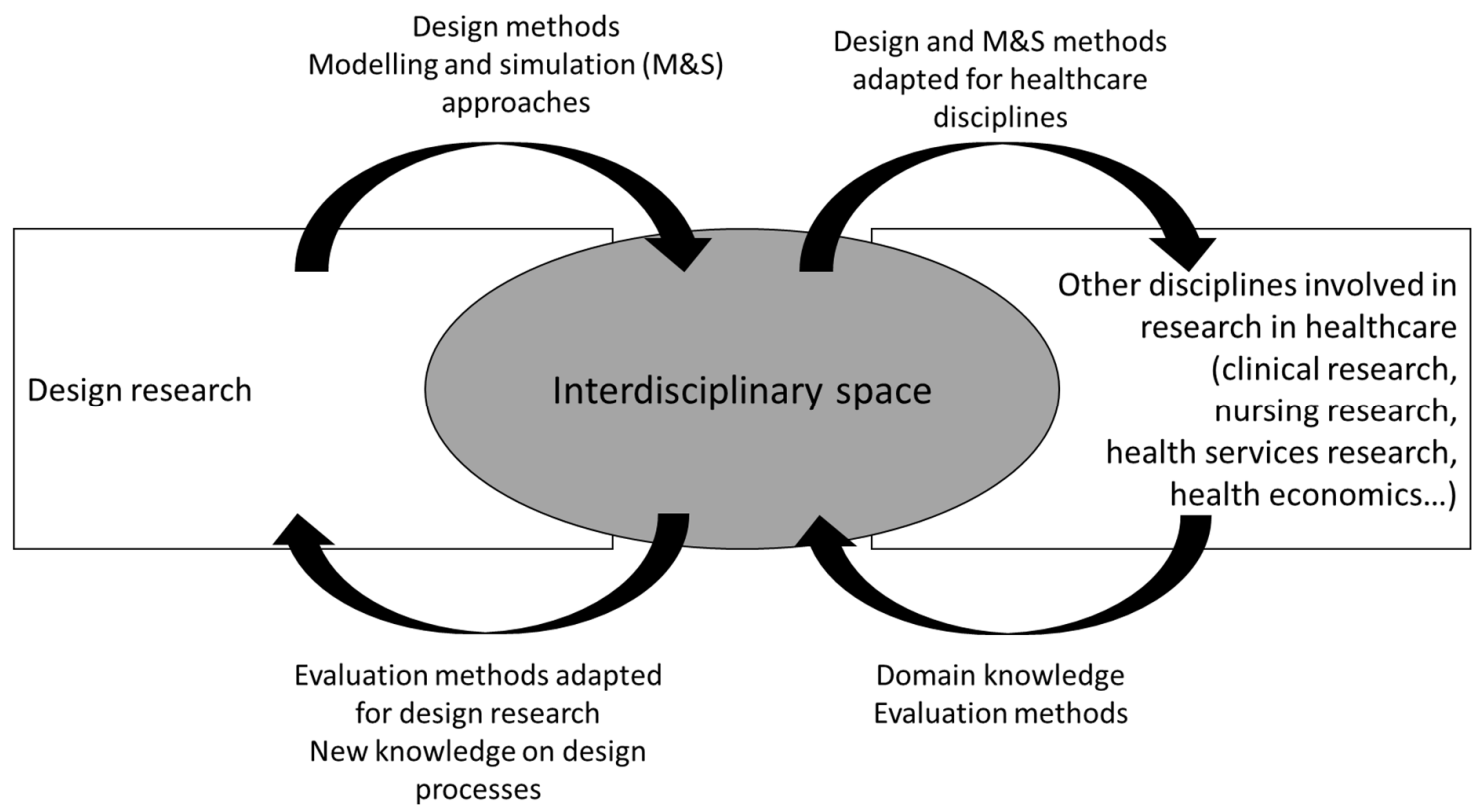

Figure 2. Interdisciplinary interactions in healthcare design research

\subsection{What design research could learn}

We believe that design research could improve through such collaborations. First, we could learn a lot on design processes as we move to a new application field. Observing practice and testing methods out of the customary industrial sectors would challenge our thinking. Besides this aspect, we believe that design has a lot to learn from the other disciplines that are involved in research in healthcare. Confronted with the need to evaluate the impact of proposed interventions in healthcare systems (both clinical, technological and organisational), researchers have developed a wide array of elaborate methods to achieve this goal. Some have proposed parallels between the evaluation of design methods and that of treatments, while identifying the limits of this model (Frey and Dym, 2006). However, many other types of evaluation methods are currently used in healthcare, which could help us understand what works in our methods, how it works, and in which context. This can only strengthen our claims when we propose our methods for application in industry and beyond (Gericke et al., 2017).

\subsection{Evidence of the emergence of a healthcare design community}

A "healthcare design" research stream can only be sustainable if it is supported by an infrastructure in education and research. Hopefully, we are seeing this in healthcare design. Dedicated academic groups have formed, for instance in Cambridge (Healthcare Design at the Cambridge Engineering Design Centre), Paris (Health Systems axis at Laboratoire Genie Industriel in CentraleSupelec), Denmark (healthcare systems design programmes at DTU's Engineering Systems division) or Stanford (Byers Center for Biodesign) and even full centres like the Centre for Health Design in California. Training curricula have also appeared, like the MRes on Healthcare \& Design at the UK Royal College of Arts. Recent design conferences have seen emergence of healthcare streams, with multiple issues and various 
perspectives. The last ICED2017 and DESIGN2016 conferences saw papers on modelling and redesigning care processes (Komashie and Clarkson, 2016; Lamé et al., 2016; Komashie et al., 2017; Lamé et al., 2017), new innovative eHealth solutions (Thorpe et al., 2017), the notion of value in healthcare systems design (Patou and Maier, 2017), users involvement (Carli Lorenzini, et al., 2017), needs identification (Thorpe et al., 2016; Rismani and Van der Loos, 2017) or worker-centered design (Andersen, 2016; Al-Masslawi et al., 2017).

When it comes to specific programmes, an interesting example is Stanford's "biodesign" programme for innovation in biomedical product-service systems. The programme relies on a need-based approach to design (Yock, 2015), and includes stage-gate concepts (Pietzsch et al., 2009). It promotes structured analysis of users' needs through in situ observation (Sista et al., 2012; Chaturvedi et al., 2015). The programme involves research and education (Yock et al., 2011).

Another example of a research programme on healthcare design is the work carried in Cambridge University around modelling of health services. Jun et al. have looked at different ways of modelling and simulating healthcare systems, they have evaluated which ones are preferred by healthcare professionals (Jun et al., 2009, 2010) and produced a selection tool for modelling and simulation methods (Jun et al., 2011). The programme includes the selection, evaluation and adaptation of industrial methods for healthcare (process models), and dissemination to the healthcare improvement research community (BMC Health Services, International Journal for Quality in Health Care). This stream of research has been continued, with projects on diagrammatic languages to represent mental health services (Komashie et al., 2017).

With such examples of design research programmes, design research societies could promote the diffusion of healthcare design and catalyse discussions on how to proceed. This would be beneficial to both healthcare and design.

\section{Acknowledgements}

The author expresses sincere thanks to Dr. Alexander Komashie for conversations on this topic and for his comments on a previous draft of this paper. However, the views expressed and the potential remaining errors are my own responsibility.

\section{References}

Al-Masslawi, D., Fels, S., Lea, R. and Currie, L.M. (2017), "Nurse-Centred Design: Homecare Nursing Workarounds to Fit Resources and Treat Wounds", Proceedings of the 21st International Conference on Engineering Design (ICED 17) Vol 3: Product, Services and Systems Design, Vancouver, Canada, August 2125, 2017, The Design Society, pp. 181-190.

Andersen, S.N. (2016), "The Process of Participatory Ergonomics Simulation in Hospital Work System Design", Proceedings of the 14th International Design Conference, Cavtat, Dubrovnik, Croatia, May 16-19, 2016, The Design Society.

Appleby, J., Galea, A. and Murray R. (2014), The NHS Productivity Challenge, The King's Fund, London, UK.

Banta, D. (2003), “The Development of Health Technology Assessment”, Health Policy, Vol. 63 No. 2, pp. 121132. https://doi.org/10.1016/S0168-8510(02)00059-3

Barth, A., Caillaud, E. and Rose, B. (2011), "How to Validate Research in Engineering Design?", Proceedings of the 18th International Conference on Engineering Design (ICED 11), Lyngby/Copenhagen, The Design Society.

Blessing, L.T.M. and Chakrabarti, A. (2009), DRM, a Design Research Methodology, Springer London, London. https://doi.org/10.1007/978-1-84882-587-1

Borry, P., Schotsmans, P. and Dierickx, K. (2006), "Evidence-Based Medicine and Its Role in Ethical DecisionMaking: Evidence-Based Medicine and Ethical Decision-Making”, Journal of Evaluation in Clinical Practice, Vol. 12 No. 3, pp. 306-311. https://doi.org/10.1111/j.1365-2753.2006.00548.x

Brailsford, S.C., Harper, P.R., Patel, B. and Pitt, M. (2009), "An Analysis of the Academic Literature on Simulation and Modelling in Health Care", Journal of Simulation, Vol. 3 No. 3, pp. 130-140. https://doi.org/10.1057/jos.2009.10

Campbell, N.C., Murray, E., Darbyshire, J., Emery, J., Farmer, A. et al. (2007), "Designing and Evaluating Complex Interventions to Improve Health Care”, BMJ, Vol. 334, pp. 455-459. https://doi.org/10.1136/bmj.39108.379965.BE 
Carli Lorenzini, G., Olsson, A. and Larsson, A. (2017), "User Involvement in Pharmaceutical Packaging Design - a Case Study", Proceedings of the International Conference on Engineering Design (ICED), University of British Columbia, Vancouver, Canada, August 21-25, 2017, The Design Society, pp. 41-50.

Chassin, M.R., Kosecoff, J., Solomon, D.H. and Brook, R.H. (1987), "How Coronary Angiography Is Used. Clinical Determinants of Appropriateness", JAMA, Vol. 258 No. 18, pp. 43-47.

Chaturvedi, J., Logan, A., Narayan, G. and Kuttappa, S. (2015), “A Structured Process for Unmet Clinical Need Analysis for Medical Device Innovation in India: Early Experiences”, BMJ Innovations, Vol. 1 No. 3, pp. 8187. https://doi.org/10.1136/bmjinnov-2014-000010

Clarkson, P.J., Bogle, D., Dean, J., Tooley, M., Trewby, J. et al. (2017), Engineering Better Care. [online] Royal Academy of Engineering, Academy of Medical Sciences \& Royal College of Physicians. Available at: http://www.raeng.org.uk/publications/reports/engineering-better-care

Clarkson, P.J., Buckle, P., Coleman, R., Stubbs, D., Ward, J. et al. (2004), "Design for Patient Safety: A Review of the Effectiveness of Design in the UK Health Service”, Journal of Engineering Design, Vol. 15 No. 2, pp. 123-140. https://doi.org/10.1080/09544820310001617711

Crowe, S., Turner, S., Utley, M. and Fulop, N.J. (2017), "Improving the Production of Applied Health Research Findings: Insights from a Qualitative Study of Operational Research”, Implementation Science, Vol. 12 No. 1, pp. 112. https://doi.org/10.1186/s13012-017-0643-3

Denis, J.-L., Lamothe, L. and Langley, A. (2001), "The Dynamics of Collective Leadership and Strategic Change in Pluralistic Organizations", Academy of Management Journal, Vol. 44 No. 4, pp. 809-837. https://doi.org/10.2307/3069417

Duong, T.A. (2016), Usage for 'New' Service Design and Integration in a Healthcare System: The Example of Teledermatology, PhD thesis, Châtenay-Malabry, Université Paris Saclay, France.

Frey, D.D. and Dym, C.L. (2006), "Validation of Design Methods: Lessons from Medicine", Research in Engineering Design, Vol. 17 No. 1, pp. 45-57. https://doi.org/10.1007/s00163-006-0016-4

Georgopoulos, B.S. and Matejko, A. (1967), "The American General Hospital as a Complex Social System", Health Services Research, Vol. 2 No. 1, pp. 76-112.

Gericke, K., Eckert, C.M. and Stacey, M. (2017), "What Do We Need to Say about a Design Method?", Proceedings of the International Conference on Engineering Design (ICED), University of British Columbia, Vancouver, Canada, August 21-25, 2017, The Design Society.

Glasgow, R.E., Green, L.W., Klesges, L.M., Abrams, D.B., Fisher, E.B. et al. (2006), "External Validity: We Need to Do More", Annals of Behavioral Medicine, Vol. 31 No. 2, pp. 105-108. https://doi.org/10.1207/s15324796abm3102_1

Gray, A.M. and Wilkinson, T. (2016), "Economic Evaluation of Healthcare Interventions: Old and New Directions", Oxford Review of Economic Policy, Vol. 32 No. 1, pp. 102-121. https://doi.org/10.1093/oxrep/grv020

Greene, M., Papalambros, P.Y. and McGowan, A.-M. (2016), "Position paper: Designing complex systems to support interdisciplinary cognitive work", Proceedings of the 14th International Design Conference, Dubrovnik, Croatia, The Design Society.

Greenhalgh, T., Annandale, E., Ashcroft, R., Barlow, J., Black, N. et al. (2016), “An Open Letter to The BMJ Editors on Qualitative Research", BMJ, Vol. 352, pp. 563. https://doi.org/10.1136/bmj.i563

Holmström, J., Ketokivi, M. and Hameri, A.-P. (2009), "Bridging Practice and Theory: A Design Science Approach", Decision Sciences, Vol. 40 No. 1, pp. 65-87. https://doi.org/10.1111/j.1540-5915.2008.00221.x

Jahangirian, M., Naseer, A., Stergioulas, L., Young, T., Eldabi, T. et al. (2012), "Simulation in Health-Care: Lessons from Other Sectors", Operational Research, Vol. 12 No. 1, pp. 45-55. https://doi.org/10.1007/s12351010-0089-8

Jahangirian, M., Taylor, S.J.E., Eatock, J., Stergioulas, L.K. and Taylor, P.M. (2015), “Causal Study of Low Stakeholder Engagement in Healthcare Simulation Projects", Journal of the Operational Research Society, Vol. 66 No. 3, pp. 369-379. https://doi.org/10.1057/jors.2014.1

Jarzabkowski, P. and Fenton, E. (2006), "Strategizing and Organizing in Pluralistic Contexts", Long Range Planning, Vol. 39 No. 6, pp. 631-48. https://doi.org/10.1016/j.lrp.2006.11.002

Johannesson, P. and Perjons, E. (2014), An Introduction to Design Science, Springer International Publishing, Cham. https://doi.org/10.1007/978-3-319-10632-8

Jun, G.T., Morris, Z., Eldabi, T., Harper, P., Naseer, A. et al. (2011), “Development of Modelling Method Selection Tool for Health Services Management: From Problem Structuring Methods to Modelling and Simulation Methods", BMC Health Services Research, Vol. 11, p. 108. https://doi.org/10.1186/1472-6963-11-108

Jun, G.T., Ward, J. and Clarkson, P.J. (2010), "Systems Modelling Approaches to the Design of Safe Healthcare Delivery: Ease of Use and Usefulness Perceived by Healthcare Workers”, Ergonomics, Vol. 53 No. 7, pp. 829847. https://doi.org/10.1080/00140139.2010.489653 
Jun, G.T., Ward, J., Morris, Z. and Clarkson, P.J. (2009), "Health Care Process Modelling: Which Method When?", International Journal for Quality in Health Care, Vol. 21 No. 3, pp. $214-224$. https://doi.org/10.1093/intqhc/mzp016

Klein, J.H. and Young, T. (2015), "Health Care: A Case of Hypercomplexity?", Health Systems, Vol. 4 No. 2, pp. 104-110. https://doi.org/10.1057/hs.2014.21

Komashie, A. and Clarkson, P.J. (2016), "Can Diagrams Help Improve Healthcare Systems Design and Care Delivery?", Proceedings of the 14th International Design Conference, Cavtat, Dubrovnik, Croatia, May $16-$ 19, 2016, The Design Society, pp. 1885-1894.

Komashie, A., Ray, S., Kar Ray, M. and Clarkson, P.J. (2017), "Designing Mental Health Delivery Systems: Where Do We Start?", Proceedings of the International Conference on Engineering Design (ICED), University of British Columbia, Vancouver, Canada, August 21-25, 2017, The Design Society, pp. 399-408.

Lamé, G., Stal-Le Cardinal, J. and Jouini, O. (2016), "Organizational Redesign: Insights from Ethnography before Simulation”, Proceedings of the 14th International Design Conference, Cavtat, Dubrovnik, Croatia, May 16 19, 2016, The Design Society, pp. 1895-1904

Lamé, G., Stal-Le Cardinal, J., Jouini, O., Verlinde-Carvalho, M., Tournigand, C. and Wolkenstein, P. (2017), “A Multimethodology for Hospital Process Redesign", Proceedings of the International Conference on Engineering Design (ICED), University of British Columbia, Vancouver, Canada, August 21-25, 2017, The Design Society, pp. 2220-4342.

Langley, A. and Denis, J.-L. (2011), "Beyond Evidence: The Micropolitics of Improvement”, BMJ Quality \& Safety, Vol. 20 No. 1, pp. 43-46. https://doi.org/10.1136/bmjqs.2010.046482

Levy, A., Coulthard, M., Harvey, M., Talbot, S. and Rich, G. (2015), "Tube Anchor: Development of a Small Medical Device from Concept to Market", BMJ Innovations, Vol. 1 No. 4, pp. 151-156. https://doi.org/10.1136/bmjinnov-2015-000066

Lozeau, D., Langley, A. and Denis, J.-L. (2002), "The Corruption of Managerial Techniques by Organizations", Human Relations, Vol. 55 No. 5, pp. 537-564. https://doi.org/10.1177/0018726702055005427

Malterud, K. (2001), "Qualitative Research: Standards, Challenges, and Guidelines”, The Lancet, Vol. 358 No. 9280, pp. 483-488. https://doi.org/10.1016/S0140-6736(01)05627-6

Mathews, S.C. and Pronovost, P.J. (2011), "The Need for Systems Integration in Health Care”, JAMA, Vol. 305 No. 9, pp. 934-935. https://doi.org/10.1001/jama.2011.237

Mays, N. and Pope, C. (1995), “Qualitative Research: Rigour and Qualitative Research”, BMJ, Vol. 311, pp. 109112. https://doi.org/10.1136/bmj.311.6997.109

Mays, N. and Pope, C. (2000), "Qualitative Research in Health Care. Assessing Quality in Qualitative Research", BMJ (Clinical Research Ed.), Vol. 320, pp. 50-52.

Medina, L.A., Jankovic, M., Okudan Kremer, G.E. and Yannou, B. (2013b), “An Investigation of Critical Factors in Medical Device Development through Bayesian Networks", Expert Systems with Applications, Vol. 40 No. 17, pp. 7034-7045. https://doi.org/10.1016/j.eswa.2013.06.014

Medina, L.A., Okudan Kremer, G.E. and Wysk, R.A. (2013a), "Supporting Medical Device Development: A Standard Product Design Process Model”, Journal of Engineering Design, Vol. 24 No. 2, pp. 83-119. https://doi.org/10.1080/09544828.2012.676635

Nair, K.M., Dolovich, L., Brazil, K. and Raina, P. (2008), “It's All about Relationships: A Qualitative Study of Health Researchers' Perspectives of Conducting Interdisciplinary Health Research", BMC Health Services Research, Vol. 8 No. 1. https://doi.org/10.1186/1472-6963-8-110.

Nowotny, H., Scott, P. and Gibbons, M. (2003), “Introduction: 'Mode 2' Revisited: The New Production of Knowledge", Minerva, Vol. 41 No. 3, pp. 179-94.

Papalambros, P.Y., Ahmed-Kristensen, S., Badke-Schaub, P., Bauerly, K., Boujut, J.F. et al. (2015), "Design Science: Why, What and How", Design Science, Vol. 1. https://doi.org/10.1017/dsj.2015.1

Patou, F. and Maier, A. (2017), "Engineering Value-Effective Healthcare Solutions: A Systems Design Perspective", Proceedings of the International Conference on Engineering Design (ICED), University of British Columbia, Vancouver, Canada, August 21-25, 2017, The Design Society, pp. 31-41.

Pietzsch, J.B., Shluzas, L.A., Paté-Cornell, M.E., Yock, P.G. and Linehan, J.H. (2009), "Stage-Gate Process for the Development of Medical Devices", Journal of Medical Devices, Vol. 3 No. 2, p. 021004. https://doi.org/10.1115/1.3148836

Plsek, P.E. (1997), “Systematic Design of Healthcare Processes”, Quality in Health Care, Vol. 6 No. 1, pp. 4048.

Portela, M.C., Pronovost, P.J., Woodcock, T., Carter, P. and Dixon-Woods, M. (2015), "How to Study Improvement Interventions: A Brief Overview of Possible Study Types: Table 1”, BMJ Quality \& Safety, Vol. 24 No. 5, pp. 325-236. https://doi.org/10.1136/bmjqs-2014-003620

Radnor, Z.J., Holweg, M. and Waring, J. (2012), “Lean in Healthcare: The Unfilled Promise?”, Social Science \& Medicine, Vol. 74 No. 3, pp. 364-371. https://doi.org/10.1016/j.socscimed.2011.02.011 
Reid, P.P., Compton, W.D. and Grossman, J.H. (2005), Building a Better Delivery System: A New Engineering/Health Care Partnership, National Academies Press, Washington.

Rismani, S. and Van Der Loos, H.F.M. (2017), "Improving Needs-Finding Techniques for Medical Device Development at Low Resource Environments Using Activity Theory", Proceedings of the International Conference on Engineering Design (ICED), University of British Columbia, Vancouver, Canada, August 2125, 2017, The Design Society, pp. 249-258.

Sackett, D.L., Rosenberg, W.M., Gray, J.A., Haynes, R.B. and Richardson, W.S. (1996), "Evidence Based Medicine: What It Is and What It Isn't', BMJ (Clinical Research Ed.), Vol. 312, pp. 71-72.

Seepersad, C.C., Pedersen, K., Emblemsvåg, J., Bailey, R., Allen, J.K. and Mistree, F. (2006), "The Validation Square: How Does One Verify and Validate a Design Method?”, In: Lewis, K.E., Chen, W. and Schmidt, L.C. (Eds.), Decision Making in Engineering Design, ASME, New York, NY. http://doi.org/10.1115/1.802469.ch25

Sista, A.K., Hwang, G.L., Hovsepian, D.M., Sze, D.Y., Kuo, W.T., et al. (2012), "Applying a Structured Innovation Process to Interventional Radiology: A Single-Center Experience", Journal of Vascular and Interventional Radiology, Vol. 23 No. 4, pp. 488-494. https://doi.org/10.1016/j.jvir.2011.12.029

Tako, A.A. and Robinson, S. (2014), “Is Simulation in Health Different?", Journal of the Operational Research Society, Vol. 66 No. 4, pp. 602-614. https://doi.org/10.1057/jors.2014.25

Thorpe, J.R., Forchhammer, B.H. and Maier, A. (2016), "Needs Elicitation for Novel Pervasive Healthcare Technology", Proceedings of the 14th International Design Conference, Cavtat, Dubrovnik, Croatia, May 16 - 19, 2016, The Design Society, pp. 1947-1956.

Thorpe, J.R., Forchhammer, B.H. and Maier, A. (2017), "Sensing Behaviour in Healthcare Design”, Proceedings of the International Conference on Engineering Design (ICED), University of British Columbia, Vancouver, Canada, August 21-25, 2017, The Design Society, pp. 171-181.

Tien, J.M. and Goldschmidt-Clermont, P.J. (2009), "Healthcare: A Complex Service System”, Journal of Systems Science and Systems Engineering, Vol. 18 No. 3, pp. 257-282. https://doi.org/10.1007/s11518-009-5108-Z

Tong, A., Sainsbury, P. and Craig, J. (2007), “Consolidated Criteria for Reporting Qualitative Research (COREQ): A 32-Item Checklist for Interviews and Focus Groups", International Journal for Quality in Health Care, Vol. 19 No. 6, pp. 349-357. https://doi.org/10.1093/intqhc/mzm042

van Aken, J.E. and Romme, G. (2009), "Reinventing the Future: Adding Design Science to the Repertoire of Organization and Management Studies", Organization Management Journal, Vol. 6 No. 1, pp. 5-12. https://doi.org/10.1057/omj.2009.1

van de Ven, A.H. and Johnson, P.E. (2006), "Knowledge for Theory and Practice", Academy of Management Review, Vol. 31 No. 4, pp. 802-821.

Walshe, K. and Rundall, T.G. (2001), "Evidence-Based Management: From Theory to Practice in Health Care", The Milbank Quarterly, Vol. 79 No. 3, pp. 429-457. https://doi.org/10.1111/1468-0009.00214

Wears, R.L. (2017), “Design: A Neglected Modality for Improvement”, Annals of Emergency Medicine, Vol. 69 No. 3, pp. 315-317. https://doi.org/10.1016/j.annemergmed.2016.09.026

Yock, P.G. (2015), "Needs-Based Innovation: The Biodesign Process", BMJ Innovations, Vol. 1 No. 1. https://doi.org/10.1136/bmjinnov-2014-000024

Yock, P.G., Brinton, T.J. and Zenios, S.A. (2011), "Teaching Biomedical Technology Innovation as a Discipline”, Science Translational Medicine, Vol. 3 No. 92, pp. 92cm18. https://doi.org/10.1126/scitranslmed.3002222

Young, T. and McClean, S. (2008), "A Critical Look at Lean Thinking in Healthcare”, Quality and Safety in Health Care, Vol. 17 No. 5, pp. 382-386. https://doi.org/10.1136/qshc.2006.020131

Zhong, X., Lee, H.K. and Li, J. (2017), "From Production Systems to Health Care Delivery Systems: A Retrospective Look on Similarities, Difficulties and Opportunities", International Journal of Production Research, Vol. 55 No. 14, pp. 4212-4227. https://doi.org/10.1080/00207543.2016.1277276

Dr. Guillaume Lamé, Research Associate

University of Cambridge, THIS Institute (The Healthcare Improvement Studies Institute)

Cambridge biomedical campus, CB2 0AH Cambridge, United Kingdom

Email: guillaume.lame@thisinstitute.cam.ac.uk 